\title{
SEASONAL AND INTERANNUAL VARIATIONS IN THE [OI] 630 nm ATMOSPHERIC EMISSION AS DERIVED FROM OBSERVATIONS OVER EASTERN SIBERIA IN 2011-2017
}

\author{
A.V. Mikhalev \\ Institute of Solar-Terrestrial Physics SB RAS, Irkutsk, Russia, mikhalev@iszf.irk.ru
}

\begin{abstract}
Seasonal and interannual variations in the [OI] $630 \mathrm{~nm}$ atmospheric emission are studied from observations of airglow in Eastern Siberia. Among features of seasonal variation in this emission are a pronounced summer maximum, an autumn minimum, and a strong interannual variability in winter months, as well as an increase in the correlation coefficient with a monthly mean value of the F10.7 solar activity index in periods close to equinoxes. We identify possible causes and phenomena (including solar activity) that form the
\end{abstract}

seasonal and interannual variations in the $630 \mathrm{~nm}$ atmospheric emission. In this study, we have used observational data from the Geophysical Observatory of the Institute of Solar-Terrestrial Physics of Siberian Branch of Russian Academy of Sciences (ISTP SB RAS, $52^{\circ} \mathrm{N}$, $103^{\circ} \mathrm{E}$ ) for 2011-2017.

Keywords: airglow, $630 \mathrm{~nm}$ emission, seasonal and interannual variations, solar activity.

\section{INTRODUCTION}

The most intense emission of the ionospheric Fregion in the visible spectrum is the forbidden [OI] ( $\left.{ }^{1} \mathrm{D}\right) 630 \mathrm{~nm}$ line. At night in midlatitudes under quiet geomagnetic conditions, the $630 \mathrm{~nm}$ emission is mainly excited by dissociative recombination of molecular oxygen ions $\mathrm{O}_{2}$ and nitrogen monoxide $\mathrm{NO}^{+}$ [Bates, 1978; Fishkova, 1983]. The [OI] $\left({ }^{1} \mathrm{D}\right)$ level is populated and the $630 \mathrm{~nm}$ emission glows due to the reaction involving molecular oxygen ion $\mathrm{O}_{2}$ in the following chain of reactions:

$$
\begin{aligned}
& \mathrm{O}^{+}+\mathrm{O}_{2} \rightarrow \mathrm{O}_{2}{ }^{+}+\mathrm{O}, \\
& \mathrm{O}_{2}{ }^{+}+\mathrm{e}^{-} \rightarrow \mathrm{O}^{*}\left({ }^{1} \mathrm{D}\right)+\mathrm{O}, \\
& \mathrm{O}^{*}\left({ }^{1} \mathrm{D}\right) \rightarrow \mathrm{O}\left({ }^{3} \mathrm{P}\right)+\mathrm{hv}(630.0 \mathrm{~nm}) .
\end{aligned}
$$

The $630 \mathrm{~nm}$ emission is observed in the F-region ( 200-300 km) and has a vertical profile similar to the electron density $N_{\mathrm{e}}$ at heights of its airglow. Due to $[\mathrm{O}] \sim N_{\mathrm{e}}$, this emission is often regarded as a sensitive indicator of electron density and dynamics of the upper atmosphere during heliogeophysical disturbances and phenomena of different nature such as mid-latitude auroras [Mikhalev et al., 2004] and traveling ionospheric disturbances in the $F$ layer [Adachi et al., 2011].

The first studies of interannual and long-term variations in mid-latitude emissions of the upper atmosphere were carried out in the 1920-30-s [Lord Rayleigh, Jones, 1935]. The most comprehensive data on longterm atmospheric emission variations were obtained during the latter half of the twentieth century (see, e.g., [Fukuyama, 1977]); they cover about five solar cycles (solar cycles 18-22). It can now be regarded as an established fact that long-term variations of atmospheric emissions in atomic oxygen 557.7 and $630 \mathrm{~nm}$ lines (85-115 km and 180-250 km airglow heights respectively) depend on solar activity. In various solar cycles, the intensity of the effects of solar activity in these atmospheric emissions can vary [Givishvili et al., 1996;
Mikhalev et al., 2008]. In this regard, of particular interest are variations in parameters of the upper atmosphere, including airglow, under conditions of abnormally low solar activity in solar cycle 24 compared to previous cycles [http://spaceweathernews.com]. Regular instrumental observations of airglow were made only for 5-6 recent solar cycles, and no data on the behavior of the $630 \mathrm{~nm}$ emission during a solar cycle with such characteristics have yet been obtained. Of particular importance are also likely to be the climatic changes that have occurred in recent decades, in particular in parameters of the upper atmosphere, including airglow [Shefov et al., 2006a]. This fact suggests addressing the problem of stability (or variability) of the basic characteristics of the $630 \mathrm{~nm}$ emission during different phases of the climatic changes.

This paper presents the results of a study of seasonal and interannual variations in the [OI] $630 \mathrm{~nm}$ atmospheric emission over the period 2011-2017 including growth, maxima, and decay phases of solar cycle 24 . The study is based on observations made at the ISTP SB RAS Geophysical Observatory (GO) $\left(52^{\circ} \mathrm{N} ; 103^{\circ} \mathrm{E}\right)$, located in Eastern Siberia (Tunka valley, the village of Tory).

\section{EQUIPMENT AND OBSERVATIONAL METHODS}

We have used observational data on $630 \mathrm{~nm}$ atomic oxygen emission obtained at the ISTP SB RAS GO with the patrol spectrometer SATI-1M developed from the ICP-51 spectrograph and color CCD sensor Sony ICX285AQ. The spectrograph is largely designed to study disturbances in the main emission lines and wavelength ranges (OI $557.7 \mathrm{~nm}$, OI $630 \mathrm{~nm}$, NaI 589.0$589.6 \mathrm{~nm}$, etc.) during heliogeophysical disturbances. The spectrograph provides a two-dimensional image of the arc of the celestial sphere in a wavelength range from 400 to $700 \mathrm{~nm}$. The spectrometer is oriented to the 
north with the optical axis elevated at an angle of $\sim 23^{\circ}$ above the horizon. The vertical angular field of view is $\sim 25^{\circ}$, exposure time is $260 \mathrm{~s}$. The main characteristics of the SATI-1M spectrometer are available at [http://atmos.iszf.irk.ru/ru/data/spectr]. The relative values of the $630 \mathrm{~nm}$ emission obtained from the northern direction were reduced to absolute zenith values of the $630 \mathrm{~nm}$ emission (R), tvaking into account the observations acquired by zenith photometers with tilting interference filters in 1997-2010 (solar cycle 23). The absolute calibration of measuring channels of the zenith photometers in 1997-2010 was carried out in individual periods from standard stars, in particular from $\alpha$ Auriga, and was then monitored with calibrators - stabilized light sources [Mikhalev et al., 2008; Mikhalev, 2017]. In 2010-2011, the viewing direction of the zenith photometers over night was periodically changed, coinciding in individual intervals with the viewing direction of the SATI-1M spectrometer. This allowed us, using the absolute calibration of the zenith photometers, to recalculate the absolute values for the [OI] 557.7 and $630 \mathrm{~nm}$ emissions, obtained with the zenith photometers, with respect to the SATI-1M spectrometer. The error in absolute measurements of the $630 \mathrm{~nm}$ emission intensity is $\leq 15 \%$. It is known that the $630 \mathrm{~nm}$ emission intensity decreases over night from dusk values $\sim 200-300 \mathrm{R}$ to $\sim 30-50$ R around midnight, then changes slightly until local twilight or until pre-twilight intensity enhancement associated with the beginning of twilight in the magnetoconjugate ionosphere [Fishkova, 1983]. This is due to the presence of several mechanisms of $630 \mathrm{~nm}$ emission excitation whose contribution may change depending on the time of day and heliogeophysical conditions [Toroshelidze, 1991]. We therefore analyze the seasonal and interannual variations of the $630 \mathrm{~nm}$ emission for near-midnight hours (23-01 LT).

\section{RESULTS AND DISCUSSION}

Table lists the monthly average values of the [OI] $630 \mathrm{~nm}$ emission intensity $I^{\mathrm{m}}{ }_{630}$, R obtained at ISTP SB RAS GO (Tory) in 2011-2017.

Monthly average [OI] $630 \mathrm{~nm}$ emission intensity $I^{\mathrm{m}} 630$, $\mathrm{R}$, for 2011-2017

\begin{tabular}{|c|c|c|c|c|c|r|r|r|r|r|r|r|}
\hline $\begin{array}{c}\text { Year/ } \\
\text { month }\end{array}$ & I & II & III & IV & V & VI & VII & VIII & IX & X & XI & XII \\
\hline 2011 & - & - & - & - & - & - & - & - & 61 & 33 & 16 & 13 \\
\hline 2012 & 22 & 30 & 39 & 39 & 57 & 99 & 88 & 73 & 55 & 37 & 37 & 35 \\
\hline 2013 & 33 & 37 & 39 & 50 & 66 & 96 & 124 & 111 & 55 & 38 & 56 & 67 \\
\hline 2014 & 65 & 67 & 60 & 59 & 63 & 102 & 131 & 122 & 45 & 35 & 37 & 35 \\
\hline 2015 & 36 & 50 & 59 & 66 & 59 & 96 & 117 & 88 & 51 & 38 & 39 & 46 \\
\hline 2016 & 64 & 66 & 68 & 54 & 62 & 100 & 109 & 69 & 51 & 23 & 26 & 30 \\
\hline 2017 & 29 & 27 & 34 & 47 & 78 & 102 & 59 & 58 & 33 & 20 & 22 & 28 \\
\hline
\end{tabular}

\section{Seasonal variation in the $630 \mathrm{~nm}$ emission and its peculiarities}

According to [Fishkova, 1983; Shefov et al., 2006b], the seasonal variation in the $630 \mathrm{~nm}$ emission is different for intensities obtained during different periods of night, depending on time after sunset. At midlatitudes in twilight and night hours, this emission is generated by photodissociation of molecular oxygen in the Schumann-Runge continuum [Toroshelidze, 1991], dissociative recombination [Bates,1978], and collisions with photoelectrons from a magnetoconjugated region [Shefov et al., 2006b], therefore the ratio of contributions of these mechanisms to the total $630 \mathrm{~nm}$ emission intensity at a fixed time should generally depend on latitude, longitude, local time, and solar activity.

Figure 1 presents the average seasonal variation in the [OI] $630 \mathrm{~nm}$ emission for 2011-2017, derived from GO data (a), coefficients of $I^{\mathrm{m}}{ }_{630}$ variations and correlation of $I_{630}^{\mathrm{m}}$ with the monthly average solar activity index $F 10.7$ (b). The seasonal variation in the [OI] 630 $\mathrm{nm}$ emission has some peculiarities. First, the $630 \mathrm{~nm}$ emission has a pronounced maximum in summer. Second, the greatest variability of this emission occurs in winter. At the same time there is the smallest variability in June and a small minimum in September. The data obtained by Fishkova [1983] at the observatory Abustumani (latitude $41.5^{\circ} \mathrm{N}$ ) in $1958-1971$ show that the seasonal variation in average night $630 \mathrm{~nm}$ emission intensities also has a summer maximum.

At the same time, the seasonal variation in the monthly average intensities of this emission for the beginning of night (2-3 hours after sunset) has a summer minimum and autumn-winter maximum; and six hours after sunset it is a semiannual variation with maxima during equinoxes and minima during solstices. Observations made at Ashkhabad (latitude $38^{\circ} \mathrm{N}$ ) [Korobeynikova, Nasyrov, 1974]
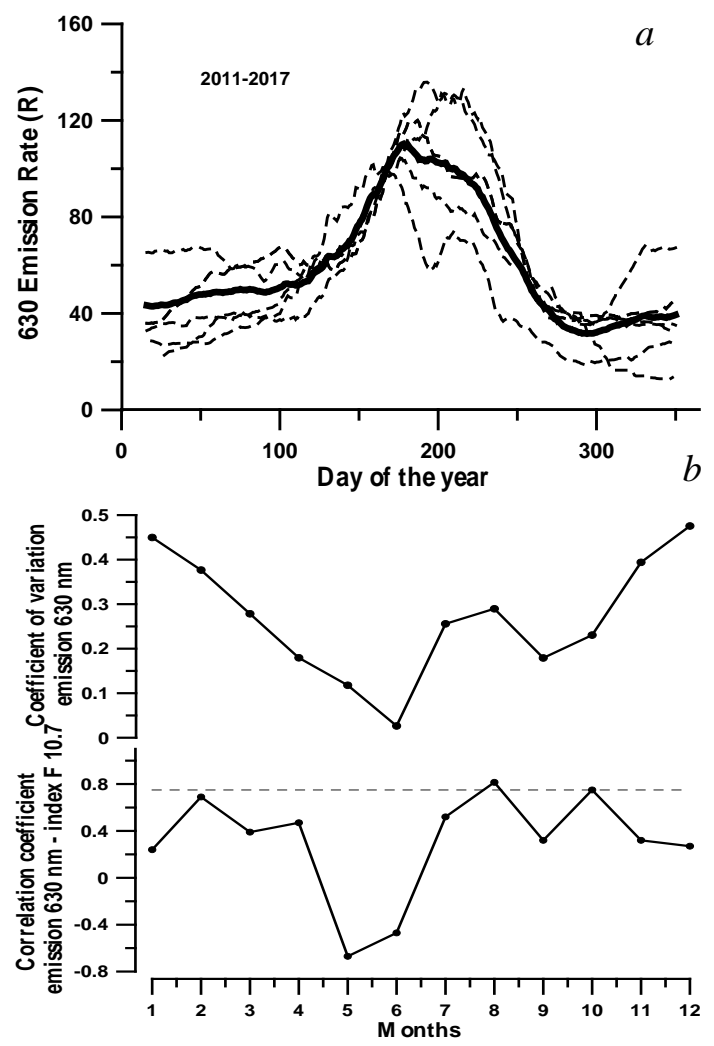

Figure 1. Seasonal variation in the $630 \mathrm{~nm}$ emission intensity (a), and coefficients of variations in the monthly average [OI] $630 \mathrm{~nm}$ emission intensity $I^{\mathrm{m}}{ }_{630}$ and correlation of $I^{\mathrm{m}}{ }_{630}$ with the monthly average index of solar activity $F 10.7(b)$ 
indicate that the average night $630 \mathrm{~nm}$ emission intensity has a maximum in summer and minima near equinoxes. In the empirical model of $630 \mathrm{~nm}$ emission variations for midlatitudes [Shefov et al., 2006b], the seasonal variation derived from data obtained by Fishkova [1983] is represented as semiannual variations with maxima during equinoxes and minima during solstices.

The pronounced summer maximum of the $630 \mathrm{~nm}$ emission intensity as derived from GO data can be attributed to the latitudinal location of the station for which in the spring-summer period (May-July) the maximum dip of the Sun below the horizon occurs at astronomical twilight. In this case, the main contribution to the emission intensity can be made by photodissociation of molecular oxygen in the Schumann-Runge continuum by dawn-to-dusk sunlight [Toroshelidze, 1991], as opposed to winter months when the main mechanism of $630 \mathrm{~nm}$ emission excitation is dissociative recombination [Bates, 1978 ]. An increase in the coefficient of correlation between $I^{\mathrm{m}}{ }_{630}$ and $F 10.7$ during periods close to equinoxes (Figure $1, b$ ) might indicate the existence of a seasonal dependence of the atomic oxygen $630 \mathrm{~nm}$ emission on solar activity similar to that identified for the atomic oxygen $557.7 \mathrm{~nm}$ emission [Fishkova et al., 2001].

\section{Interannual variations in the $630 \mathrm{~nm}$ emis- sion}

Figure 2 presents variations in the monthly average solar radio emission index $F 10.7$, atomic oxygen 630 $\mathrm{nm}$ emission intensity, and planetary $A_{\mathrm{p}}$ index over the analyzed period. The solar radio emission index $F 10.7$ was used to assess the level of solar activity; the planetary $A_{\mathrm{p}}$ index, the level of geomagnetic activity. The period of interest includes phases of growth, maximum, and decay of solar cycle 24 .

In the general case (Figure 2), there is a tendency for the $630 \mathrm{~nm}$ emission intensity to vary during cycle 24 in phase with solar cycle (in terms of minimum, maximum values $I_{630}^{\mathrm{m}}$, interpolation curves) - an increase in the emission intensity from low solar activity to high solar activity. Interpolation curves also indicate an increase in $I^{\mathrm{m}}{ }_{630}$ during a decrease in solar activity in 2015-2016, which is probably associated with an increase in geomagnetic activity (index $A_{\mathrm{p}}$ ) [Shefov et al., 2006a]. We should consider here that solar cycle 24 is characterized by very low solar activity compared to previous cycles [http://spaceweathernews.com].

Figure 3 presents average annual values of the $630 \mathrm{~nm}$ emission intensity and solar activity index F10.7 for 20122017. It is apparent that the dependence of the average annual $630 \mathrm{~nm}$ emission on solar activity is more pronounced than that of its monthly average values (a correlation coefficient of $\sim 0.72$ ). Shefov et al. [2006b] have used data on long-term variations of average annual $630 \mathrm{~nm}$ emission intensities in 1958-1992 (solar cycles 19-22) [Givishvili et al, 1996] to obtain the correlation dependence on the $F 10.7$ index $(K=0.73)$ :

$$
\Delta I_{F}=(0.0030 \pm 0.0010)(F 10.7-130) .
$$

For midnight intensities, the dependence is given

$$
\Delta I_{F}=(0.0060 \pm 0.0015)(F 10.7-130) \text {, }
$$

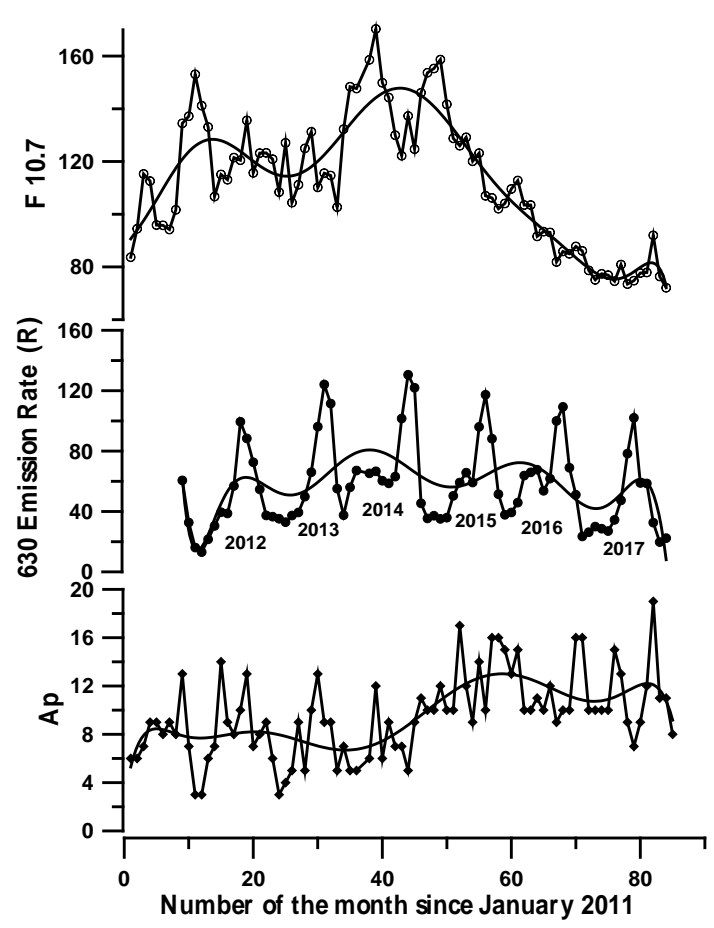

Figure 2. Variations in monthly average values: solar radio emission index $F 10.7$ (upper curve), atomic oxygen 630 $\mathrm{nm}$ emission intensity $I_{630}^{\mathrm{m}}$ (middle curve), and planetary $A_{\mathrm{p}}$ index (lower curve). Solid lines show data interpolation by polynomials of 10 th power

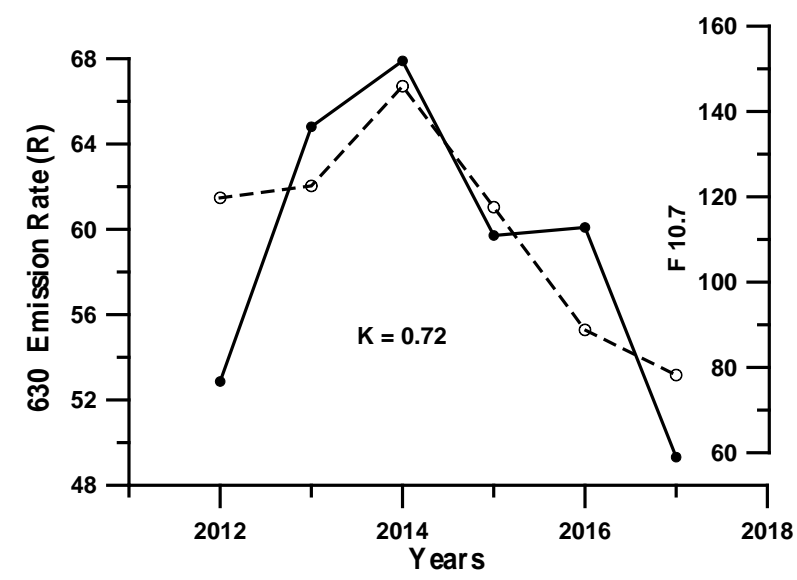

Figure 3. Average annual values of $630 \mathrm{~nm}$ emission intensity (solid line) and solar activity index F10.7 (dashed line)

where $\Delta I_{F}$ is a relative change in the $630 \mathrm{~nm}$ emission intensity.

Note that according to [Mikhalev et al., 2008] for solar cycle 23, as derived from GO data, the correlation coefficient between the average annual $630 \mathrm{~nm}$ emission and $F 10.7$ is 0.68 .

The estimated ratio between average annual $630 \mathrm{~nm}$ emission values in solar cycle 24 at maximum and minimum $I_{\max } / I_{\min }$ is $\sim 1.36$, which is slightly lower than that obtained for the mid-latitude stations Haute Provence ( 2) [Barbier, 1965] and Zvenigorod ( 2.5) [Truttse, Belyavskaya, 1975] during previous solar cycles. This value agrees, however, fairly well with that $(\sim 1.32)$ derived from formula (1) in the empirical model [Shefov et al., 2006b] in view of current average annual values 
of solar activity index F10.7 in solar cycle 24 for 2012 2017. The resulting low value of $I_{\max } / I_{\min }$ for the 630 $\mathrm{nm}$ emission reflects the peculiarity of solar cycle 24 characterized by minor solar activity variations compared to previous cycles. The dependence of average annual $630 \mathrm{~nm}$ emission intensities on F10.7 according to the data from this paper and according to expression (1) from the empirical model [Shefov et al., 2006b] are presented in Figure 4. The average annual intensities have been obtained from experimental data for all months. If, however, we ignore summer months in the experimental data when deriving the average annual intensities, the best agreement is observed between the solar activity dependence plotted from measurements and the dependence based on expression (2) of the empirical model [Shefov et al., 2006b]. This may be due to the fact that for the location of GO the contribution of summer months to average annual intensities is quite significant (see Figure 1, a). In the summer months at GO, by virtue of its geographical location, nights are short - no longer than 3-4 hours. In this case, the 630.0 $\mathrm{nm}$ emission, in view of its night variation [Shefov et al., 2006b], during the near-midnight hours has no time to be excited only by dissociative recombination as it occurs at lower-latitude stations whose data were used for constructing the empirical model of $630 \mathrm{~nm}$ emission variations [Shefov et al., 2006a, b].

Shefov et al. [2006b] observe cyclic aperiodic 630 $\mathrm{nm}$ emission variations caused by solar activity with a period 2-3 years. Curves of interpolation of monthly average $I^{\mathrm{m}}{ }_{630}$ in Figure 2 also show variations with such a period.

\section{CONCLUSION}

Basing on observations of the atomic oxygen 630 $\mathrm{nm}$ emission intensity at midlatitudes of Asia in nearmidnight hours, we have identified peculiarities of seasonal and interannual variations of this emission during solar cycle 24, which is characterized by extremely low solar activity. We have first determined the seasonal variation of the atomic oxygen $630 \mathrm{~nm}$ emission intensity for the location of the ISTP SB RAS Geophysical Observatory, which have observed the airglow for more

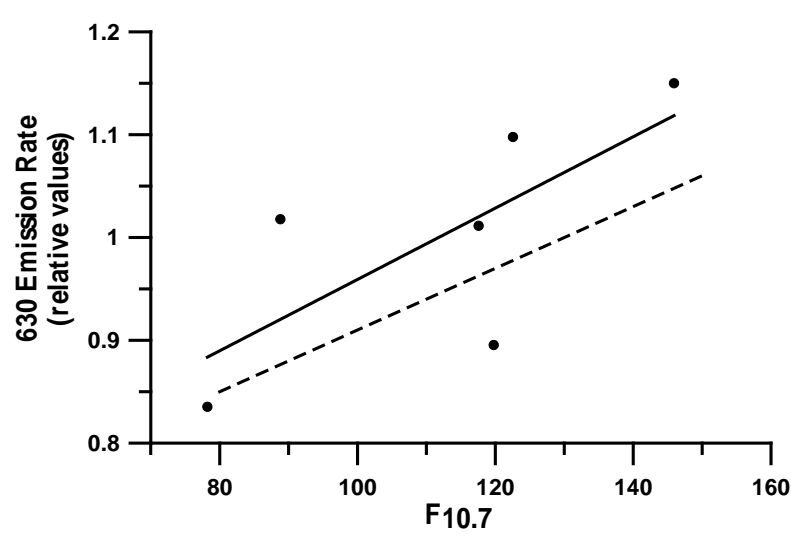

Figure 4. Average annual $630 \mathrm{~nm}$ emission intensities versus F10.7 as derived from data obtained in this paper (dots, solid line) and from the empirical model [Shefov et al., 2006b]

\section{(dashed line)}

than 20 years. Among peculiarities of the seasonal variation in this emission are a pronounced summer maximum, an autumn minimum, and a strong interannual variability in winter months, as well as an increase in the coefficient of correlation between $I^{\mathrm{m}}{ }_{630}$ and monthly average solar activity index F10.7 during periods close to equinoxes. It is noted that the well-known dependence of the $630 \mathrm{~nm}$ emission intensity in solar cycle 24 on solar activity (F10.7) remains unchanged. The obtained ratio between average annual values of the 630 $\mathrm{nm}$ emission in solar cycle 24 at solar maximum and minimum proved to be lower than that between the corresponding values obtained for mid-latitude stations during previous cycles. This may be associated with the abnormality of solar cycle 24. Coefficients of correlation between atomic oxygen $630 \mathrm{~nm}$ emission intensity and solar activity index F10.7, obtained for different solar cycles from experimental data and empirical model [Shefov et al., 2006b ], have similar values. This fact may indicate that the main mechanisms for forming the relationship between the $630 \mathrm{~nm}$ emission and solar activity during the last few solar cycles persist.

This work was performed with budgetary funding of Basic Research program II.16. This work is based on data from the optical complex of Center for Common Use “Angara”.

\section{REFERENCES}

Adachi T., Otsuka Y., Yamaoka M., Yamamoto M., Shiokawa K., Chen A.B., Hsu R.R. First satellite-imaging observation of medium-scale traveling ionospheric disturbances by FORMOSAT-2/ISUAL. Geophys. Res. Lett. 2011, vol. 38, L04101. DOI: 10.1029/2010GL046268.

Barbier D. Variations de l'intensite des principales radiations de la luminescence atmospherique nocturne avec le cycle solaire. [Intensity variations of the mean radiation of the night airglow of atmospheric emission in the solar cycle]. Ann. Geophys. 1965, vol. 21, pp. 265-274. (In French).

Bates D.R. Forbidden oxygen and nitrogen lines in the nightglow. Planet. Space Sci. 1978, vol. 26, no. 10, pp. 897-912.

Fishkova L.M. Nighttime airglow of the mid-latitude Earth upper atmosphere. Tbilisi, Metsniereba Publ., 1983, 271 p. (In Russian).

Fishkova L.M., Martsvaladze N.M., Shefov N.N. Seasonal variations in the $557.7 \mathrm{~nm}$ atomic oxygen emission dependence on solar activity and long-term trend. Geomagnetizm i aeronomiya [Geomagnetism and Aeronomy]. 2001, vol. 41, no. 4. pp. 557-562. (In Russian).

Fukuyama K. Airglow variations and dynamics in the lower thermosphere and upper mesosphere II. Seasonal and long-term variations. J. Atmos. Terr. Phys. 1977, vol. 39, no. 1, pp. 1-14.

Givishvili G.V., Leshchenko L.N., Lysenko E.V., Perov S.P., Semenova A.I., Sergeyenko N.P., Fishkova L.M., Shefov N.N. Long-term trends of some characteristics of the Earth atmosphere. Measurement results. Izvestiya RAN. Fizika atmosfery i okeana [Izvestiya. Atmospheric and Oceanic Physics]. 1996, vol. 32, no. 3, pp. 329-339. (In Russian).

Korobeinikova M.L, Nasyrov G.A. Structural features of the $\lambda 6300 \AA$ emission. Geofizichesky Byulleten' [Geophysical Bulletin]. Moscow, Nauka Publ., 1974, no. 27, pp. 35-39. (In Russian)

Lord Rayleigh, Jones S.H. The light of the night sky: 
analysis of the intensity variations at three stations. Proc. Roy. Soc. 1935, vol. 151, no. A872, pp. 22-55.

Mikhalev A.V. Features of the [OI] $557.7 \mathrm{~nm}$ atmospheric emission variation. Optika atmosfery i okeana [Atmospheric and Oceanic Optics]. 2017, vol. 30, no. 4, pp. 296-300. (In Russian).

Mikhalev A.V., Beletsky A.B., Kostyleva N.V., Chernigovskaya M.A. Midlatitude airglow at the south of East Siberia during strong geomagnetic storms on October 29-31 and November 20-21, 2003. Kosmicheskie issledovaniya [Cosmic Res.]. 2004, vol. 42, no. 6, pp. 616-621. (In Russian).

Mikhalev A.V., Medvedeva I.V., Kostyleva N.V., Stoeva P. Manifestation of solar activity in the $557.7 \mathrm{~nm}$ and $630 \mathrm{~nm}$ atmospheric emission variations in solar cycle 23. Optika atmosfery i okeana [Atmospheric and Oceanic Optics]. 2008, vol. 21, no. 5, pp. 425-431. (In Russian).

Shefov N.N., Semenov A.I., Khomich V.Yu. Upper Atmosphere Airglow as an Indicator of Its Structure and Dynamics. Moscow, GEOS Publ., 2006a, 741 p. (In Russian).

Shefov N.N., Semenov A.I., Yurchenko O.T. Empirical model for variations in the $630 \mathrm{~nm}$ atomic oxygen emission. 1. Intensity. Geomagnetizm i aeronomiya [Geomagnetism and Aeronomy]. 2006b, vol. 46, no. 2, pp. 250-260. (In Russian).
Toroshelidze T.I. Analys of Aeronomy Problems by the Upper Atmosphere Airglow. Tbilisi, Metsniereba Publ., 1991, 216 p. (In Russian).

Truttse Yu.L., Belyavskiy V.D. 6300 Å red oxygen emission and upper atmosphere density. Geomagnetizm i aeronomiya [Geomagnetism and Aeronomy]. 1975, vol. 15, no. 1, pp. 101-104. (In Russian).

URL: http://atmos.iszf.irk.ru/ru/data/spectr (accessed March 15, 2018)

URL: http://spaceweathernews.com (accessed March 15, 2018).

How to cite this article

Mikhalev A.V. Seasonal and interannual variations in the [OI] $630 \mathrm{~nm}$ atmospheric emission as derived from observations over Eastern Siberia in 2011-2017. Solar-Terrestrial Physics. 2018. vol. 4, iss. 2. pp. 58-62. DOI: 10.12737/stp-42201809. 